\title{
UJI EFEK ANTIPIRETIK EKSTRAK ETANOL DAUN MIANA(COLEUS SCUTELLARIOIDES [L]) BENTH PADA TIKUS PUTIH JANTAN GALUR WISTAR (RATTUS NORVEGICUS)
}

\author{
Sri Gentari Benjamin ${ }^{1)}$, Adithya Yudistira ${ }^{1)}$, Henki Rotinsulu ${ }^{1)}$ \\ ${ }^{1)}$ Program Studi Farmasi FMIPA UNSRAT Manado, 95115
}

\begin{abstract}
This study aims to determine the antipyretic effect of miana leaves extract (Coleus scutellariodes L Bent) in white male rats strain wistar. The subjects of this study were 15 white male rats, which were divided into 5 groups, namely the negative control group (1\% CMC), the positive control group (Paracetamol), and the treatment group (miana leaf extracts). This type of research is a laboratory experiment, which carried out on the test animals based on a Completely Randomized Design (CRD) by testing the antipyretic effect carried out by administering the DPT-Hb vaccine. The observed response was in the form of data retrieval related to rat temperature after 2 hours of DPT-hb vaccine administration. Body temperature measurements were carried out before administering the vaccine, then successively at the 30th, 60th, 90th, and 120th minutes, respectively. The results showed miana leaf extracts at a dose of 25 $\mathrm{mg}, 50 \mathrm{mg}$ and $75 \mathrm{mg}$ had an antiperetic effect in white male rats but the dose $75 \mathrm{mg}$ provides the most effective antipyretic effect. Thus it can be concluded that the ethanol extracts of miana leaves has an antipyretic effect in white male rats, which were induced orally.
\end{abstract}

Keywords: Antipyretics, Miana Leaves, Male White Rat.

\begin{abstract}
ABSTRAK
Penelitian ini bertujuan untuk mengetahui Efek Antipiretik Ekstrak daun Miana (Coleus scutellariodes [L] Bent) pada Tikus Putih Jantan Galur Wistar. Subjek penelitian ini ialah 15 ekor tikus putih jantan yang dibagi menjadi 5 kelompok yaitu kelompok kontrol negatif (CMC 1\%), kelompok kontrol positif (Parasetamol), dan kelompok perlakuan (ektrak daun miana).Jenis penelitian ini ialah eksperimental laboratorium yang akan dilakukan pada hewan uji berdasarkan Rancangan Acak Lengkap (RAL) dengan pengujian efek antipiretik dilakukan dengan cara memberikan vaksin DPT-Hb. Respon yang diamati yaitu berupa pengambilan data terkait suhu tikus setelah 2 jam pemberian vaksin DPT-hb. Pengukuran suhu tubuh dilakukan sebelum pemberian Vaksin, kemudian berturut-turut pada menit ke-30, 60, 90, dan 120. Hasil penelitian menunjukan ekstrak daun Miana dengan dosis $25 \mathrm{mg}$, $50 \mathrm{mg}$ dan $75 \mathrm{mg}$ memiliki efek antiperetik pada tikus putih jantan namun dosis $75 \mathrm{mg}$ memberikan efek antipiretik yang paling efektif. Dengan demikian dapat disimpulkan bahwa ekstrak daun miana memiliki efek antipiretik pada tikus putih jantan yang di induksi secara oral.
\end{abstract}

Kata kunci : Antipiretik, Daun Miana, Tikus Putih Jantan 


\section{PENDAHULUAN}

Indonesia sebagai negara yang

berada di daerah tropis mempunyai

keanekaragaman hayati yang sangat besar, kaya akan bahan baku obat, sehingga fitofarmaka merupakan suatu pilihan pengobatan yang menarik dan dapat terus dikembangkan. Indonesia memiliki kurang lebih 30.000 spesies tanaman dan 7.000 spesies termasuk tanaman berkhasiat yang telah dilakukan penelitian secara ilmiah. Pengobatan tradisional di Indonesia, menggunakan bahan-bahan yang terdapat di alam sekitar merupakan bagian dari kebudayaan bangsa yang turun temurun (Hayati dkk., 2012).

Salah satu tanaman obat yang sering digunakan masyarakat untuk pengobatan ialah Miana. Daun miana atau yang biasa disebut dengan tanaman iler menurut Lisdawati (2008) mempunyai nama ilmiah (Coleus scutellarioides[L] benth). Senyawa kimia yang terkandung dalam daun miana (Coleus scutellarioides benth) adalah golongan minyak atsiri, flavonoid, alkaloid, steroid, tanin,dan saponin.Flavonoid memiliki berbagai macam bioaktivitas. Bioaktivitas yang ditunjukkan antara lain efek antipiretik, analgetik dan antiinflamasi (Wijayakusuma, 2001). Flavonoid bekerja sebagai inhibitor cyclooxygenase (COX) yang berfungsi memicu pembentukan prostaglandin. Prostaglandin berperan dalam proses inflamasi dan peningkatan suhu tubuh. Apabila prostaglandin tidak dihambat maka terjadi peningkatan suhu tubuh yang akan mengakibatkan demam (Andriana, 2007).

Antipiretik merupakan obat yang menekan suhu tubuh pada keadaan
demam.Pada umumnya demam adalah suatu gejalah bukan merupakan penyakit tersendiri. Pada suhu $40-41^{\circ} \mathrm{C}$ barulah terjadi terjadi situasi kritisyang bisa menjadi fatal,karena tidak terkendal oleh tubuh (Tjay Tan Hoam dan Kirana,2007).Obat-obat antipiretik secara umum dapat di golongkan dalam beberapa golongan yaitu golongan salisilat, (misalnya aspirin, salisilamid), golongan para-aminofel (misalnya acetaminophen, fenasetin) dan golongan pirazolon (misalnya fenilbutason dan metamizole) (Wilmana, 2007).Pemberian obat-obat antipiretik bertujuan untuk menurunkan suhu pada hipotalamus dengan cara mencegah terbentuknya prostaglandin dengan menghambat enzim siklooksigenase (Gunawan, 2009).

Berdasarkan latar belakang diatas dan menurut pengamatan, masyarakat Kabupaten Kepulauan Sangihe khususnya Tahunasering menggunakan daun Miana (Coleus scutellarioides [L] Benth) sebagai antipiretik atau penurun demam. Karena belum ada pengujian secara ilmiah tentang daun Miana (Coleus scutellarioides [L] Benth) sebagai antipiretik maka hal inilah yang menarik perhatian peneliti untuk menguji efek antipiretik ekstrak etanol daun Miana (Coleus scutellarioides [L]) Benthpada Tikusputih jantan (Rattus norvegicus) yang diinduksi vaksin DPT-HB.

\section{METODOLOGI PENELITIAN}

Jenis dan Lokasi Penelitian Jenis Penelitian

Penelitian ini ialah eksperimental laboratorium yang menggunakan tikus putih jantan sebagai hewan percobaan. 


\section{Waktu dan Tempat Penelitian}

Penelitian dilaksanakan pada Agustus 2019 sampai September 2019 di Laboratorium Farmasi Lanjut F-MIPA UNSRAT.

\begin{abstract}
Alat dan bahan
Alat Penelitian

Alat-alat yang digunakan dalam penelitian ini yaitu kandang, sarung tangan, tempat air minum dan makan hewan, alatalat gelas, timbangan analitik, erlenmeyer, sarung tangan, batang pengaduk, sudip, lumpang dan alu, blender, kasa streril, masker,toples, ayakan mesh 65, disposable syringe $3 \mathrm{ml}$, NGT no 3.5, gunting, tabung reaksi, vakum evaporator, hot plate, kertas saring dan termometer digital.
\end{abstract}

\section{Bahan Penelitian}

Bahan yang digunakan Miana (Coleus scutellarioides [L] Benth), etanol 95\%, aquades, parasetamol, CMC, vaksin DPT-HB dan tikus putih jantan sebanyak 15 ekor.

\section{Rancangan Penelitian}

Jenis penelitian ini ialah eksperimental laboratorium yang akan dilakukan pada hewan uji berdasarkan Rancangan Acak Lengkap (RAL) dengan 5 perlakuan di ulang sebanyak 3 kali sehinggah jumlah tikus yang akan digunakan sebanyak 5 perlakuan $\times 3$ ulangan $=15$ hewan uji tikus putih dan masing-masing hewan uji akan diberikan vaksin DPT-HB.

\section{Variabel Penelitian:}

Variabel Bebas

Variable bebas pada penelitian ini yaitu ekstrak daun miana sebanyak 25 $\mathrm{mg} / \mathrm{kg} \mathrm{BB}, 50 \mathrm{mg} / \mathrm{kg}$ BB dan $75 \mathrm{mg} / \mathrm{kg}$ BB.

\section{Variabel Terikat}

Variable terikat pada penelitian ini yaitu penurunan suhu tubuh hewan uji tikus putih galur wistar.

\section{Prinsip Penelitian}

Dilakukan pengukuran awal suhu rektal pada hewan uji kemudian hewan uji diinduksi demam dengan vaksin DPT-Hb setelah itu suhu rektal hewan uji diukur kembali stelah pemberian vaksin DPT-Hb. Untuk ekstrak daun miana diberikan secara per oral setelah diinduksi demam dengan vaksin DPT-Hb kemudian diukur kembali suhu hewan uji untuk mengetahui efek antipiretik daun miana.

\section{Langkah Kerja}

\section{Pengumpulan dan pengambilan sampel}

Sampel yang digunakan berupa daun miana diambil sebanyak $4 \mathrm{~kg}$, dibersihkan, dan dicuci dibawah air mengalir sampai bersih. Setelah itu ditiriskan, lalu dikeringkan dengan cara diangin-anginkan. Setelah itu, Sampel yang telah kering dihaluskan dengan menggunakan blendersampai menjadi serbuk. Serbuk yang dihasilkan diayak menggunakan ayakan mesh 200, hingga diperoleh serbuk yang halus dan seragam. Hasilnya dimasukkan ke dalam wadah gelas tertutup (Gunawan, 2004). 


\section{Ekstraksi}

Ekstrak daun miana dibuat dengan cara maserasi. Dimana sebanyak $400 \mathrm{~g}$ dimasukkan dalam toples dan direndam dengan pelarut etanol $95 \% 2000 \mathrm{ml}$. Wadah di tutup menggunakan aluminium foil dan biarkan selama 5 hari sampell sesekali di aduk. Setelah lima hari, saring sampel yang di rendam dengan menggunakan kertas saring dan menghasilkan filtrat 1 dan ampas 1. Kemudian ampas yang ada direndam kembali denga etanol 95\% $1200 \mathrm{ml}$ di tutup dengan aluminium foil selama dua hari sambil sesekali di aduk. Setelah dua hari sampel tersebut disaring menggunakan kertas saring, menghasilkan filtrat II dan ampas II.Filtrat I dan II digabungkan,kemudian dievaporasi menggunakan rotaryevaporator, sehingga diperoleh ekstrak kental daun miana. Ekstrak kental yang dihasilkan dibiarkan pada suhu ruangan hinggaseluruh pelarut etanol menguap. Setelah itu ekstrak ditimbang dan disimpan dalam wadah tertutup sebelum digunakan untuk pengujian(Anonim, 1986).

\section{Pembuatan CMC 1\%}

Sebanyak $1 \mathrm{~g} \quad$ serbukCMC ditimbang kemudian dimasukan dalam gelas beaker kemudian di campurkan dengan 100 $\mathrm{ml}$ aquades dan dihomogenkan dengan cara pemanasan menggunakan hot plate, kemudian di dinginkan. Perbandingan aquades dan CMC adalah 100:1 artinya $1000 \mathrm{ml}$ aquades terdapat 1 gram CMC.

\section{Pemilihan Hewan Uji}

Hewan uji yang digunakan dalam penelitian ini adalah Tikus Putih Jantan sebanyak 15 ekor dengan berat badan $150 \mathrm{~g}$ - 300g yang dibagi menjadi 5 kelompok perlakuan dimana setiap kelompok terdiri dari 3 ekor tikus. Kelompok pertama diberi kontrol negative (CMC 1\%), kelompok ke-2 diberi control positif (parasetamol), kelompok ke-3 diberi ektrak daun miana 25 $\mathrm{mg} / \mathrm{KgBB}$, kelompok ke-4 diberi ektrak daun miana $50 \mathrm{mg} / \mathrm{KgBB}$, kelompok ke-5 diberi ektrak daun miana $75 \mathrm{mg} / \mathrm{KgBB}$.

\section{Induksi penyebab demam}

Berdasarkan penelitian uji antipiretik yang telah dilakukan oleh junaedi (2007), demam diinduksi dengan penyuntikkan vaksin DPT-Hb 0,5 ml/200 g BB tikus secara intramuscular.

\section{Perhitungan Dosis}

\section{Ekstrak Daun Miana}

Pada pemberian ekstrak etanol daun Miana (Coleus scutellarioides Linn. Benth) berdasarkan berat tikus :

Variasi dosis yang akan digunakan:

Kelompok Perlakuan (KP1)

$=25 \mathrm{mg} \times 0,018 \mathrm{~g}=0,0045 \mathrm{~g} / 10 \mathrm{ml}$

Kelompok Perlakuan (KP2)

$=50 \mathrm{mg} \times 0,018 \mathrm{~g}=0,009 \mathrm{~g} / 10 \mathrm{ml}$

Kelompok Perlakuan (PK3)

$=75 \mathrm{mg} \times 0,018 \mathrm{~g}=0,0135 \mathrm{~g} / 10 \mathrm{ml}$

Tikus yang digunakan pada penelitian ini mempunyai BB 150-300.

\section{Kontrol Positif (+)}

Antipiretik yang akan digunakan dalam penelitian ini adalah parasetamol tablet $500 \mathrm{mg}$. dengan dosis lazim manusia dewasa adalah $500 \mathrm{mg}$, maka dosis parasetamol untuk tikus adalah 500 x 0,018 
$=0,09 \mathrm{~g} / 10 \mathrm{ml}$. (0.018 merupakan faktor konversi dosis manusia ke tikus putih)

\section{Pengujian antipiretik Ekstrak Daun Miana}

Tikus putih galur wistar yang telah diadaptasikan selama 1 minggu dipuasakan selama 12 jam dan hanya diberi minum. Semua hewam uji diukur suhu rektal sebelum dan sesudah diinduksi dengan vaksin DPT-HB. Hewan uji diinduksi secara intramuscular. Selanjutnya, tikus putih diberikan sediaan oral dimana control negatife diberikan suspensi CMC dan kontol positif diberikan parasetamol dan kelompok perlakuan diberi ekstrak daun miana . Suhu rektal hewan diuji diukur tiap 30 menit hinggah ke-120 menit setelah diinduksikan dengan vaksin DPT-HB. Pengukuran suhu dilakukan menggunakan termometer digital kemudian masing - masing kelompok diberi perlakuan sebagai berikut :

a. Kelompok 1

Diberi perlakuan Na-CMC 1\% sebagai kontrol negatif

b. Kelompok 2

Diberikan paracetamol dengan pemberian per oral. Dosis $0,09 \mathrm{mg} / 10$ $\mathrm{ml}$

c. Kelompok 3

Diberikan perlakuan ekstrak etanol daun Miana per oral dengan dosis $25 \mathrm{mg}$

d. Kelompok 4

Diberikan perlakuan pemberian ekstrak etanol daun Miana per oral dengan dosis $50 \mathrm{mg}$

e. Kelompok 5

Diberikan perlakuan pemberian ektrak etanol daun Miana dengan per oral dosis $75 \mathrm{mg}$

\section{Pengolahan Data}

Data berupa suhu awal $\left(\mathrm{T}_{0}\right)$, suhu 2 jam setelah pemberian vaksin dan suhu selang setiap 30 menit setelah perlakuan dianalisa secara statistik menggunakan metode Anova untuk mengetahui pengaruh ekstrak daun miana terhadap penurunan suhu tubuh hewan uji yang diinduksi vaksin DPT-HB

\section{HASIL DAN PEMBAHASAN Hasil}

Pada penelitian ini di peroleh serbuk simplisia tanaman miana sebanyak 400gram. yang dimaserasi menggunakan pelarut etanol 95\% sebanyak 2 kali siklus maserasi diperoleh ekstrak kental sebanyak 43,4 gram.

\section{Hasil Perlakuan Uji}

Uji pengaruh perlakuan terhadap penurunan suhu tubuh tikus jantan putih GalurWistar terlebih dahuludilakukan pada tubuhnya dalam keadaan demam, oleh karena itu diperlukan demam buatan.Untuk mendemamkan tubuh $M$. musculus yaitu dengan diberi vaksin DPT sebanyak 0,5 $\mathrm{mg} / \mathrm{KgBB}$ yang diinjeksikan secara intramuscular, hasilnya setelah dua jam suhu tubuhtikus jantan putih galur Wistarsudah berada padakisaran antara $36,24-37,86{ }^{\circ} \mathrm{C}$, dimana suhu awal tubuh $M$. musculus sebelum diberi vaksinberada pada kisaran $34,4-36,46{ }^{0} \mathrm{C}$. Adapun data hasil pengukuran suhu demam dan suhu sesudah diberi ekstrak daun miana dapat dilihat pada Tabel 1. 
PHARMACONJurnal Ilmiah Farmasi - UNSRAT Vol. 9 No. 1 FEBRUARI 2020 ISSN 2302 - 2493

Tabel 1. Hasil Pengukuran Suhu Tubuh

\begin{tabular}{l|c|c|c|c|c|c|c}
\hline \multirow{2}{*}{ Kelompok } & \multicolumn{7}{|c}{ Pengukuran (C) } \\
\cline { 2 - 7 } Negatif & Replikasi & T & T0 & T1 & T2 & T3 & T4 \\
\hline \multirow{3}{*}{ Positif } & 1 & 35,5 & 37,5 & 37,6 & 37,5 & 37,5 & 37,3 \\
& 2 & 36,4 & 37,3 & 37,7 & 37,3 & 37,3 & 37 \\
& 3 & 36,3 & 36,5 & 37,1 & 37,4 & 37,4 & 37,2 \\
\hline \multirow{3}{*}{ Dosis 25mg } & 1 & 35,8 & 37,4 & 36,9 & 36,4 & 35,9 & 35,5 \\
& 2 & 35,4 & 37 & 36,4 & 36,2 & 35,8 & 35,4 \\
& 3 & 36,3 & 36,4 & 35,9 & 35,6 & 35,2 & 34,8 \\
\hline \multirow{3}{*}{ Dosis 50mg } & 1 & 36,3 & 37,6 & 37 & 36,6 & 36,4 & 36,2 \\
& 2 & 36,2 & 37,6 & 37 & 36,6 & 36,3 & 36 \\
& 3 & 36,4 & 37,6 & 37,1 & 36,7 & 36,5 & 36,2 \\
\hline \multirow{3}{*}{ Dosis 75mg } & 1 & 34,4 & 37,8 & 37,2 & 36,8 & 36,4 & 36 \\
& 2 & 35,7 & 36,6 & 35,5 & 35 & 34,8 & 34,5 \\
& 3 & 35,5 & 37,2 & 36,8 & 36,4 & 36,1 & 35,8 \\
\hline
\end{tabular}

Hasil pengujian antipiretik terhadap tikus putih jantan galur wistaryang dilakukan dengan pemberian Vaksin DPT-HB sebagai penginduksi, suspensi CMC sebagai kontrol negatif dan pemberian suspensi parasetamol sebagai pembanding. Tikus yang diberikan perlakuan ekstrak daun miana secara oral menunjukkan perubahan suhu yang berbeda - beda. Hasil pengamatan dari pemberian ektrak daun miana terhadap efek antipiretik dalam menurunkan susu diperlihatkan pada
Tabel1. Dari berbagai perlakuan suhu tubuh tikus setelah diinduksikan dengan vaksin DPT-HB mengalami kenaikan $\pm 1,5^{\circ} \mathrm{C}$ dari selisih suhu normal kesuhu demam tikus. Adapun gejala yang ditunjukkan tikus saat suhu mengalami kenaikan atau demam yaitu aktivitas tikus menjadi berkurang,tidak mau makan maupun minum, bulu berdiri, tubuh lemas, suhu menjadi meningkat, dan katup mata kelihatan sayu. 
PHARMACONJurnal IImiah Farmasi - UNSRAT Vol. 9 No. 1 FEBRUARI 2020 ISSN 2302 - 2493

Tabel 4.2 Rata - rata suhu tubuh tikus di setiap observasi

\begin{tabular}{l|c|r|r|r|r|r}
\hline Kelompok & \multicolumn{1}{|c|}{ T } & \multicolumn{1}{c|}{ T0 } & \multicolumn{1}{c|}{ T1 } & \multicolumn{1}{c|}{ T2 } & \multicolumn{1}{c}{ T3 } & \multicolumn{1}{c}{ T4 } \\
\hline Negatif & 36,07 & 37,10 & 37,47 & 37,40 & 37,40 & 37,17 \\
\hline Positif & 35,83 & 36,93 & 36,40 & 36,07 & 35,63 & 35,23 \\
\hline Dosis 25mg & 36,30 & 37,60 & 37,03 & 36,63 & 36,40 & 36,13 \\
\hline Dosis 50mg & 35,20 & 37,20 & 36,50 & 36,07 & 35,77 & 35,43 \\
\hline Dosis 75mg & 35,60 & 36,50 & 36,23 & 36,07 & 35,80 & 35,43 \\
\hline
\end{tabular}

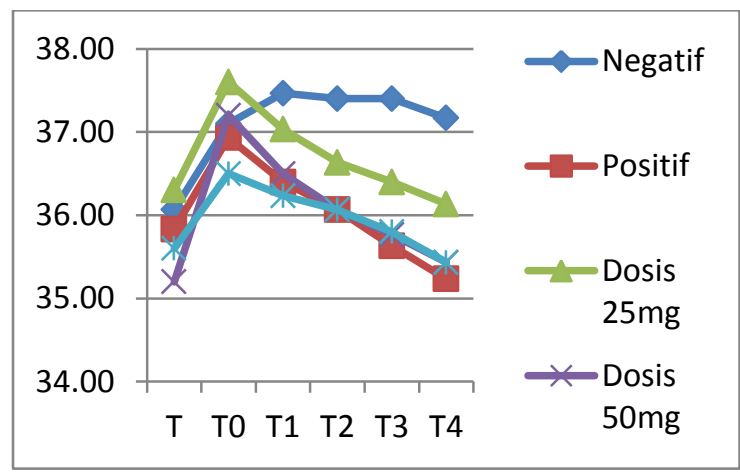

\section{Pembahasan}

Penelitian ini dilakukan dengan menggunakan tikus putih jantan galur wistar yang dibagi dalam 5 kelompok pengujian yaitu pengujian terhadap ekstrak daun Miana secara oral dengan Dosis $25 \mathrm{mg} 50$ $\mathrm{mg}, 75 \mathrm{mg}$, dan masing-masing per 200 gram BB, sebagai control positif digunakan paracetamol 0,09 mg/ 200 gram BB tikus dan kontrol negatif yang digunakan CMC 1 mg/ 200 gram BB.

Penggunaan parasetamol sebagai kontrol positif karena parasetamol adalah salah satu obat analgetik non opioid bekerja melalui penghambatan siklooksigenase. Parasetamol menghambat siklooksigenase sehingga konversi asam arakhidonat menjadi prostaglandin terganggu. Setiap obat menghambat siklooksigenase secara berbeda. Parasetamol menghambat siklooksigenase pusat lebih kuat dari pada aspirin, inilah yang menyebabkan
Parasetamol menjadi obat antipiretik yang kuat melalui efek pada pusat pengaturan panas. Parasetamol hanya mempunyai efek ringan pada siklooksigenase perifer. Inilah yang menyebabkan Parasetamol hanya menghilangkan atau mengurangi rasa nyeri ringan sampai sedang. Parasetamol tidak mempengaruhi nyeri yang ditimbulkan efek langsung prostaglandin, ini menunjukkan bahwa parasetamol menghambat sintesa prostaglandin dan bukan blokade langsung prostaglandin. Obat ini menekan efek zat pirogen endogen dengan menghambat sintesa prostaglandin, tetapi demam yang ditimbulkan akibat pemberian prostaglandin tidak dipengaruhi, demikian pula peningkatan suhu yang disebabkan oleh latihan fisik (Aris 2009).

\section{KESIMPULAN}

Berdasarkan hasil yang di peroleh dapat di simpulkan bahwa ekstrak etanol daun Mian (Coleus scutellarioides [L] benth) menunjukkan efek antipiretik dan mampu menurunkan suhu tikus putih jantan galur wistar (Rattus norvegicus). Terdapat pengaruh antara konsentrasi dosis ekstrak etanol daun miana dengan efek antipiretik pada tikus jantan galur wistar, dimana ekstrak etanol daun miana dengan dosis 75 
PHARMACONJurnal Ilmiah Farmasi - UNSRAT Vol. 9 No. 1 FEBRUARI 2020 ISSN 2302 - 2493

mg memberikan efek antipiretik yang signifikan.

\section{SARAN}

1. Peneliti menyarankan agar terdapat penambahan variasi dosis serta waktu pengamatan untuk mendapatkan hasil yang lebih komprehensif terkait efek antipiretik dari daun Miana (Coleus scutellarioides benth.)

2. Peneliti menyadari masih terdapat berbagai kelemahan dalam pelaksanaan penelitian yang mungkin mempengaruhi hasil yang didapat saat ini. Peneliti menyarankan untuk dilakukan penelitian lanjutan dengankondisi yang jauh lebih terkontrol agar mendapatkan hasil yang lebih maksimal.

\section{DAFTAR PUSTAKA}

Andriana, D. 2007. Efek analgesik Perasan Daun Biduri pada Mencit dengan Metode Geliat.Skripsi.

Gunawan,2009. Farmakologi dan terapi. Edisi kelima Jakarta : UI Press.

Gunawan, A. 2007. Perbandingan Efek Analgesik antara Paracetamol dengan Kombinasi Paracetamol dan Kafein pada Mencit. Jurnal Biomedika, 1(1).

Lisdawati, V. 2008. Karakteristik Daun Miana ( Plectranthus scutellarioides (L) Bth) Dan Buah Sirih (Piper Betle L.) secara Fisiko Kimia dari Ramuan Lokal Anti Malaria daerah Sulawesi Utara.Media Litbang Kesehatan Volume XVIII NOMOR 4.
Wilmana, F. P., \& Gans, S., 2007. Analgesik-Antipiretik Analgesik Antiinflamasi Farmakologi dan Terapi. Edisi 4,230-233, Jakarta Bagian Farmakologi Fakultas Kedokteran UI. 